\title{
El Parque Natural Marítimo-Terrestre de Cabo de Gata-Níjar. Un espacio excepcional
}

\author{
José Guirado Romero \\ Director General de Gestión del Medio Natural \\ Consejería de Medio Ambiente \\ Junta de Andalucía \\ María Navarro Domínguez \\ José Fernández-Palacios Carmona
}

Técnicos de la Consejería de Medio Ambiente

El Parque Natural Marítimo-Terrestre de Cabo de Gata-Níjar, se sitúa en el sureste peninsular español, en la provincia de Almería. Constituye un territorio con una superficie de 37.570 hectáreas terrestres y 12. 126 marinas, con una altitud máxima de $562 \mathrm{~m}$ y mínima de $-60 \mathrm{~m}$ en los fondos marinos. Afecta a los municipios de Almería, Carboneras y Níjar. La personalidad de este espacio se fundamenta por dos aspectos: su carácter semiárido, siendo uno de los pocos espacios protegidos de Europa de vocación subdesértica y estepárica, y albergar los 50 kilómetros de costa acantilada mejor conservados del litoral mediterráneo español.

El territorio emergido del Parque presenta dos grandes unidades fisiográficas: la sierra (Sierra del Cabo de Gata) y la llanura costera (Bahía de Almería).

Gran parte de su peculiaridad ecológica, ambiental y paisajística tiene su origen en la naturaleza de los substratos volcánicos existentes. Las sierras del Cabo de Gata son las representantes emergidas de una amplia región volcánica que se extiende sumergida bajo el Mar de Alborán, evidenciando un pasado y una evolución geológica común con el Norte del continente africano. El volcanismo, que ha dejado una significativa impronta en el paisaje de este territorio, tuvo su inicio hace unos 15 millones de años, en la era Terciaria (Mioceno), y se prolongó en el tiempo hasta hace unos 6-7 millones de años.

Su origen se relaciona con extrusiones de magma a favor del adelgazamiento de la corteza terrestre en la relación de contacto entre las grandes placas continentales europea y africana, en el contexto de la formación de la Cordillera Bético-Rifeña Las excepcionales condiciones de observación permiten pasear por un verdadero museo natural: coladas de lava, rocas piroclásticas, ignimbritas, aglomerados, estratovolcanes, domos volcánicos, calderas volcánicas, disyunciones columnares, diques, etc.

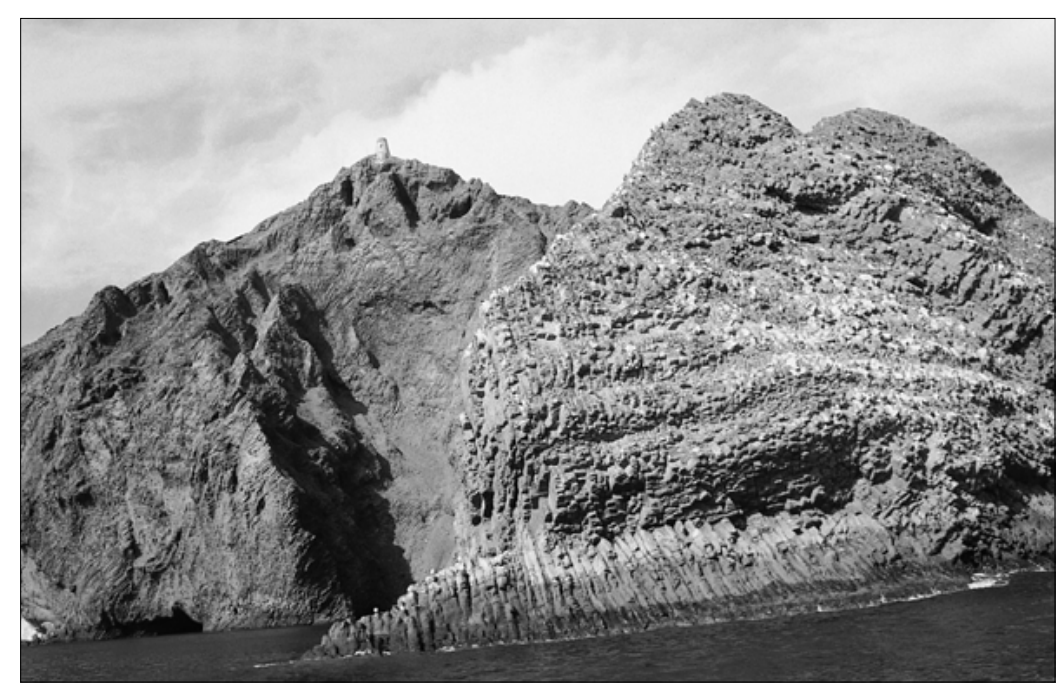

Acantilado de Vela Blanca

La fase hidrotermal asociada al volcanismo ha sido, por otra parte, la responsable de la formación de yacimientos minerales singulares, como el oro nativo de Rodalquilar, plata, plomo y zinc, ancestralmente beneficiados en el ámbito del Parque, o las bentonitas del Cabo, actualmente en explotación. La minería, sin duda, ha sido una de las actividades humanas que han dejado su huella sobre el paisaje de este territorio, además de un importante patrimonio arqueo-industrial, con sus dos mejores exponentes en el embarcadero de mineral de Agua Amarga y el complejo minero de Rodalquilar.

Al finalizar la fase extrusiva, el mar, más cálido entonces, invadió la cuenca conformando un archipiélago volcánico. En la línea de costa, sobre los volcanes emergentes, se desarrollaron arrecifes de coral (en el Messiniense, hace unos 5,5millones de años). Estas formaciones arrecifales, hoy fósiles, conforman unos relieves también característicos del Parque: las "mesas", depósitos tabulares, elevados, de singular belleza. Este complejo arrecifal es, por otro lado, uno de los mejores conservados y de mayor valor científico del Mediterráneo occidental, clave para el estudio y comprensión de la evolución geológica y ambiental de la historia reciente del Mediterráneo. En el resto de la cuenca marina, en las zonas más profundas, se depositan entre tanto calcarenitas, margas y otros materiales procedentes de la denudación de los relieves emergidos circundantes.

La otra gran unidad fisiográfica, la Bahía de Almería, al Sur del Parque, se relaciona sin embargo con la dinámica cuaternaria ( 100.000 años). El mar abandona progresivamente el área, dejando tras de sí un conjunto de terrazas marinas (tirrenienses) que en 


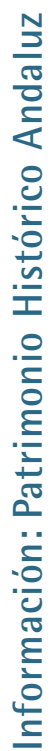

Praderas de Posidonia Oceanica. Banco de verrugatos (Sciaena umbra).
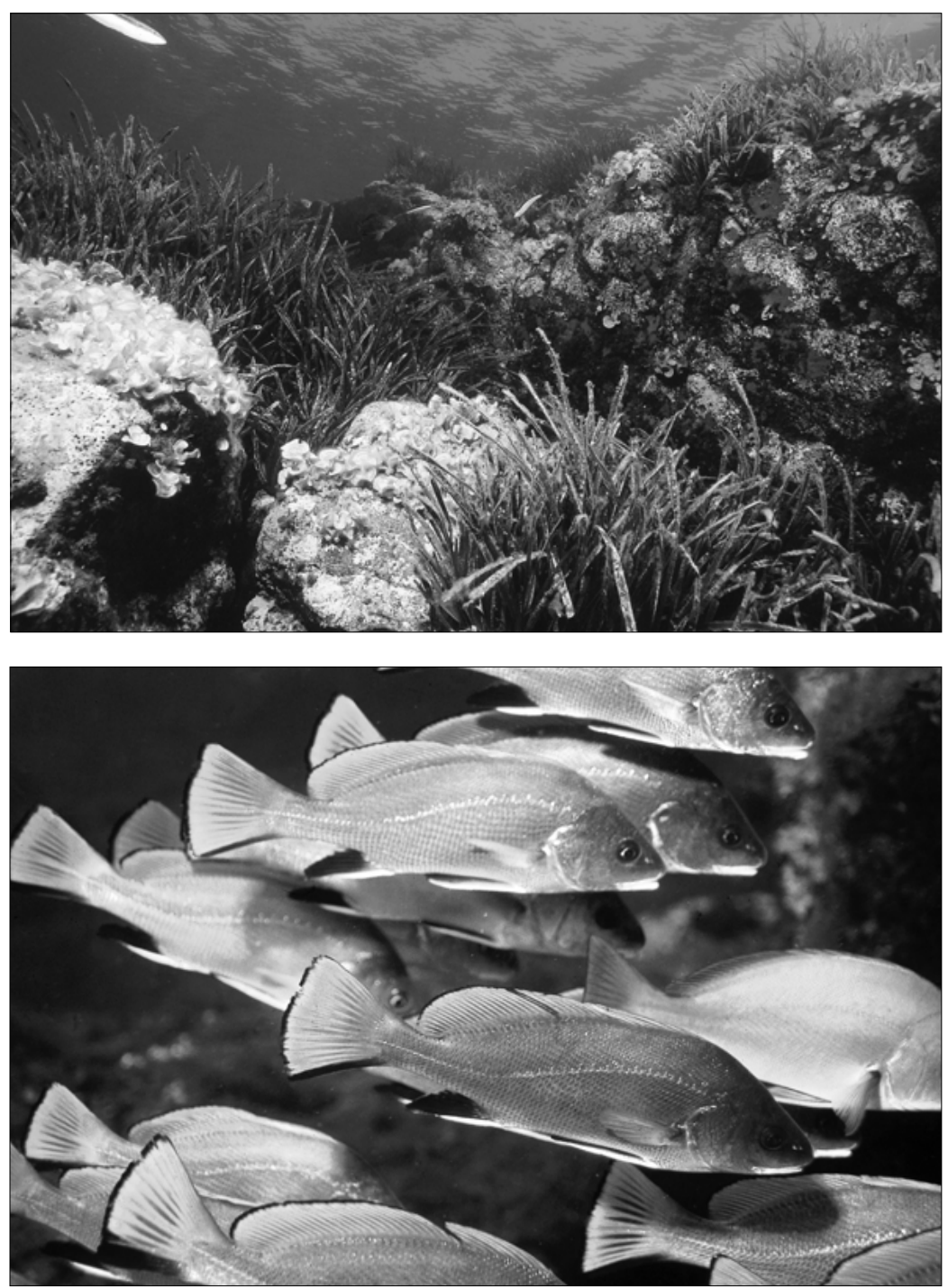

En este espacio árido, con suelos pobres, escasamente desarrollados, y condiciones climatológicas desfavorables, se desarrolla, sin embargo, una de las mayores riquezas florísticas del continente europeo, con un número de elementos vegetales inventariados que se sitúa cercano al millar de taxones. Ello es posible gracias al efecto amortiguador del mar, que proporciona una humedad ambiental que compensa la escasez de lluvias y suaviza las temperaturas, lo que posibilita una cubierta vegetal propia de ambientes más húmedos y la supervivencia de especies muy sensibles, que no soportan temperaturas inferiores a los $0^{\circ} \mathrm{C}$.

De todo este elenco florístico, entre un 92 y un 95\% de los elementos son plantas autóctonas, con un 75\% de elementos de distribución exclusivamente mediterránea perfectamente adaptadas a condiciones ambientales de extremada dureza. De ellos, un 12\% son endemismos de distribución iberoa-fricana: cornical o sarguilla (Periploca angustifolia), azufaifo o arto blanco (Ziziphus lotus), orobal (Whitania frutescens), esparto (Stipa tenacissima), retama (Retama sphaerocarpa), bolina (Genista umbellata), zagua o salado negro (Salsolaverticillata), salado blanco o mata conejera (Salsola Webbii), rascamoños o aulaga del desierto (Launaea arborescens), etc.

Un | | - |4\% son plantas con una distribución exclusiva en el contexto peninsular, entre las que destacan endemismos ibéricos (2\%), béticos (3\%), del sureste peninsular (4\%), murciano-almerienses (4\%) y locales (diez especies, 0,6\%), restringidos a nivel mundial a determinadas áreas del Parque. Entre estos últimos cabe señalar: el dragoncillo del Cabo (Antirrhinum charidemi), becerrilla del Cabo (Antirr-hinum pallaresianum), "falso" azafrán del Cabo o despachapastores del Cabo (Androcymbium europaeum), zama-rrilla o tomillo macho del Cabo (Teucrium charidemi), cla-velina del Cabo (Dianthus charidemi), gordolobo del Cabo (Verbascum charidemi), cardo heredero del Cabo (Atracty-lishumilis), aulaga mora (Ulex canescens), cabezuela del Cabo (Cheirolophus mansanetianus) y espuelilla del Cabo(Linaria benitoi).

Un recorrido por el Parque nos acerca a la observación de magníficas poblaciones de palmito y cornical, que escalan las abruptas laderas volcánicas, mientras que grupos de lentiscos, aladiernos, acebuches y coscojas, pocas y de porte arbustivo, buscan refugio en barrancos umbríos. Densas formaciones de tomiIlo, esparto, albaida y romero tapizan las laderas y llanuras prelitorales. Barronales, comunidades de algodonosa, poleo de mar, azuzena marina y sabinas se adaptan a las severas condiciones ambientales de los arenales y dunas litorales. Multitud de margaritas de mar tiñen los singulares matorrales adaptadosa los acantilados marinos y pequeñas islas costeras. Galerías de adelfas y tarajes colorean las ramblas en el inicio de la época estival. Paisaje vegetal al que se suman las huertas, con palmeras datileras, higueras, algarrobos, granados, limoneros, etc., conformando reducidos espacios de excepcional semejanza a la agricultura de oasis y que sin duda son corresponsa- 
bles de las sensaciones evocadoras del paisaje africano en este territorio.

La riqueza faunística no es menor. Los espartales y tomillares dan cobijo a una completa comunidad de aves esteparias: cogujada montesina, terrera marismeña, terrera común, curruca tomillera y alondra de Dupont, junto con alcaravanes, ortegas o churras y sisones, que habitan las llanuras pedregosas de la estepa.

La vegetación arbustiva, principalmente el azufaifar, acoge multitud de especies: aves como el alcaudón real; mamíferos como el zorro, el conejo, el erizo y el tejón; reptiles como la lagartija colirroja, el lagarto ocelado y la culebra bastarda.

Los relieves volcánicos son lugar óptimo para aves como el águila perdicera, búho real, halcón peregrino y roquero solitario, entre otros. Las oquedades volcánicas están ocupadas por la collalba negra, coIlalba rubia y camachuelo trompetero, cuya área de distribución europea se restringe al sureste de la provincia de Almería.

Los barrancos que mantienen agua todo el año, con vegetación rica y densa, son refugio seguro para la gineta y reptiles como el galápago leproso o la víbora hocicuda y anfibios como el sapo corredor.

Merece especial atención dentro de este espacio la antigua albufera, las Salinas de Cabo de Gata, con gran diversidad de ambientes. En ella pueden observarse todo el año centenares de flamencos, que pueden contarse por miles durante el paso prenupcial (primavera) y postnupcial (verano). Junto a ellos más de 80 especies de aves pueden verse durante todo el año: ánade real, ánade silbón, ánade rabudo, pato cuchara, tarroblanco, garza real, garceta común, chorlitos, chorlitejos, archibebes, correlimos, avocetas, cigüeñuelas, gaviota de audouin, etc. son los principales pobladores de las salinas.

En el medio marino del Parque, con las aguas más limpias y transparentes de todo el mediterráneo español, se encuentra una de las praderas más occidentales de Posidonia oceanica, delimitando las Ilanuras de arena y fango de los accidentados fondos rocosos.

Se han catalogado más de 1.300 especies distintas de organismos marinos en este espacio natural, lo que constituye un claro índice de su elevada diversidad. Las llanuras de arena y fango, cuya monotonía rompen las praderas de una fanerógama marina, $C y$ modocea nodosa, albergan un mundo vivo nada estridente, a veces difícil de observar: tallerina, navaja, corneta, coquina, erizo de corazón, estrellas de arena gris y anaranjada, lenguado de arena, araña, tembladera, etc.

En los accidentados fondos de roca volcánica y en los acantilados sumergidos la vida, por el contrario, se manifiesta con extraordinarios cambios de formas y color: algas, esponjas, anémonas de mar, moluscos,
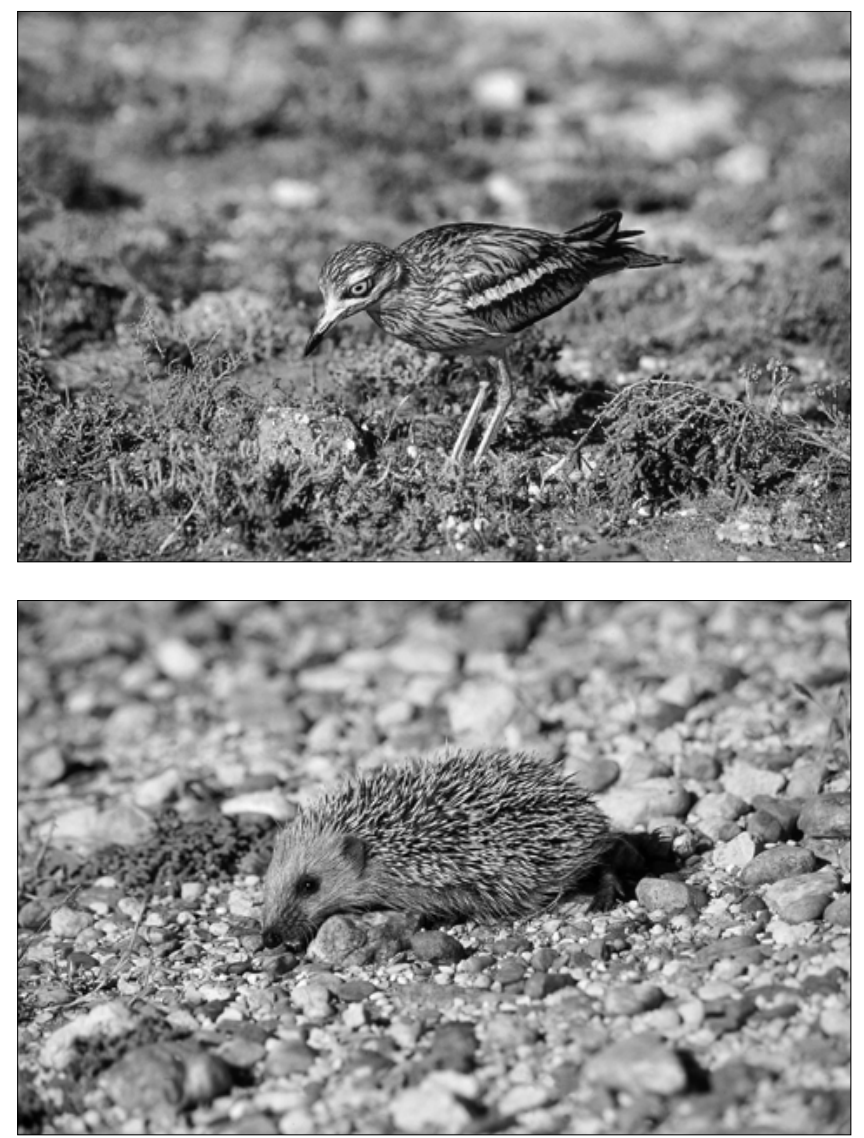

Alcaraván (Burhinus Oedicnemus).

entre los que destaca la Nacra (Pinna nobilis) el bivalvo más grande de todo el Mediterráneo (hasta 80 centímetros de longitud), la oreja de mar, dátil de mar, arca pelosa, ostra de perro; crustáceos, cangrejo moruno, galeras; equinodermos, coombros de mar, castañasde mar, erizos, estrella espinosa roja; tunicados y comunidades de carácter precoralígeno y coralígeno constituidas por especies de los géneros Myriapora clatherinea, Astroides, etc.

Junto a estas formas de vida, los peces, algunos de ellos de muy alto valor comercial y económico, como el mero o el abadejo, junto con ellos doncellas, galanes, tordos, pez verde, cabrillas y serranos, castañuelas, herreras y sargos, morenas, congrios, además de toda una serie de elementos de presencia habitual en aguas mediterráneas: lechas, espetones, salmonetes, bogas, salemas, besugos, brecas, obladas, dentones, chuclas, palometas, golondrina de mar, etc.

No es raro, por último, el avistamiento en este litoral privilegiado de grandes reptiles y cetáceos, como la tortuga boba, los delfines listados, común y mular y los calderones negro y gris.

Uno de los rasgos más significativos del Parque es su carácter antrópico. La huella de las distintas culturas se hace hoy día visible en numerosos rasgos y elementos, otorgándole junto con sus valores naturales, un incuestionable valor antropológico, ya que permite seguir, paso a paso, cómo el hombre ha explotado sus recursos. El Parque Natural Cabo de Gata- 


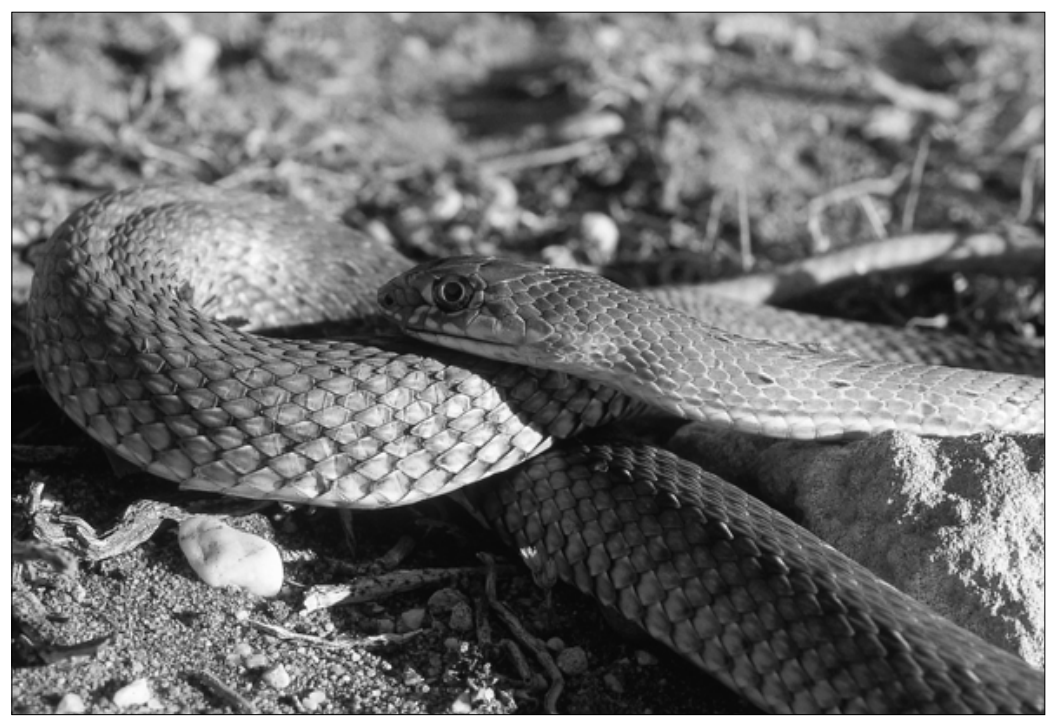

Culebra bastarda (Malpolom monpessulanus).

\section{DATOS DE INTERÉS}

Nombre: Cabo de Gata-Nijar

Régimen de protección: Parque Natural Marítimo-Terrestre

Legislación:

- Decreto 314/87 (Declaración), BOJA nº 6, de 21/01/1988

- Ley 2/1989 (Inventario), BOJA no 60, de 27/07/1989

- Decreto 418/94 (Plan de Ordenación y Plan Rector), BOJA ño 203, de 22/12/1989

Otras figuras de protección:

- Reserva de la Biosfera

- Designación como Geoparque

- Zona de Especial Protección de Aves (ZEPA)

- Su principal zona húmeda, Salinas de Cabo de Gata, incluida en el Convenio RAMSAR

- Su principal zona estepárica, Las Amoladeras, es Refugio de Caza y Estación Zoológica

- Plan Especial de Protección del Medio Físico de la Provincia de Almería

- Plan General de Ordenación Urbana de Almería

- Normas Subsidiarias de Planeamiento Urbanístico de Níjar y Carboneras

Autoridad ambiental: Consejería de Medio Ambiente. Junta de Andalucía

Superficie: 37.570 hectáreas terrestres y 12.126 marinas

Localización (latitud y longitud): $36^{\circ} 51^{\prime} \mathrm{N}$ y $2^{\circ} 6^{\prime} 0$

Municipios beneficiados: Almería, Carboneras y Níjar

Población: 3.500 (residentes en el Parque) y 185.000 residentes en los municipios del Parque.

Relevancia ecológica: Origen volcánico, clima semiárido, carácter marítimo-terrestre, hábitats de interés: estepa mediterránea, formaciones dunares, albufera-salinas, acantilados litorales y praderas de fanerógamas marinas, patrimonio arqueológico, etnográfico y antropológico.

Época aconsejada para visita: Septiembre a mayo (otoño, invierno y primavera)

\section{Equipamientos para uso público ofertados por la Consejería de Medio Ambiente:}

- Información e interpretación: Centro de Visitantes (Las Amoladeras), Oficina de Información y Tienda Verde (Rodalquilar), Kioskos/Puntos de Información estacionales (Las Sirenas, Pozo de Los Frailes, Isleta del Moro, Amatista y Los Muertos), Centros de Servicios Litorales de Monsul y Torregarcía.

- Educación Ambiental: Centro E.A. "El Bujo", Aula del Mar "El Corralete", Jardín Botánico "El Albardinal", Vivero y Aula de Jardinería de Rodalquilar.

- Observación: Miradores (5), Senderos (22) y Observatorios Ornitológicos (2).

- Dinamización Cultural: Sede administrativa y de servicios del Parque Natural y centro de Exposiciones, ambos en Rodalquilar y Castillo de San Felipe (Los Escullos).
Níjar se constituye así en una muestra viva de la interacción del hombre con la naturaleza.

El patrimonio histórico y cultural es, así, rico y variado. Pobladores fenicios y romanos ocuparon sucesivamente estos territorios para explotar sus recursos. Testimonios de su paso han quedado en las explotaciones mineras y en los talleres de adoquines volcánicos de los acantilados de Punta Baja, El Barronal, La Polacra y El Playazo, en las fábricas de salazón de pescados y púrpura de Torre García, etc.

La costa, dado su valor estratégico, se encuentra salpicada de multitud de torres vigías musulmanas y fuertes defensivos, como el de San Felipe en los Escullos, construidos en el Siglo XVIII por orden de Carlos III, a fin de proteger los habitantes de las incursiones piratas provenientes del Norte de África.

No dejan de ser significativos aprovechamientos como el del agua en un clima extremadamente árido, que da lugar a modelos hidráulicos y de riego peculiares, o la forma en la que la arquitectura se adapta al rigor climático. Una sola planta de escaso alzado, volúmenes cúbicos reducidos, muy pocos huecos de conexión con el exterior, cubiertas planas impermeables y ausencia absoluta de aristas constituyen elementos esenciales de la tipología arquitectónica popular del Parque. Cal, arena del lugar, vigas de madera o tallos secos de pitaco, que soportan capas sucesivas de cañizo palmito y launa, han sido los materiales de construcción autóctonos utilizados hasta el primer tercio del siglo XX. La arquitectura popular presenta una gran riqueza en las aldeas y cortijadas, jalonadas con construcciones muy significativas no sólo en forma de viviendas, también pozos, norias, aljibes y molinos, en los que predominan las formas redondeadas.

\section{Reserva de la Biosfera}

En 1997 el Parque Natural fue declarado coincidiendo con el décimo aniversario de creación, Reserva de la Biosfera por parte de la UNESCO.

Esta declaración supone, no sólo, el reconocimiento a nivel mundial de la fuerte personalidad y el gran valor ecológico y ambiental de este espacio, sino también el esfuerzo que desde el Gobierno autónomo andaluz se viene realizando por la aplicación e incentivación de políticas y estrategias de desarrollo compatibles con el mantenimiento de la biodiversidad y el uso sostenido de los recursos naturales y culturales, principios básicos del desarrollo sostenible. Las Reservas de la Biosfera son "zonas protegidas de medios terrestres y costeros, representativos, que son reconocidas internacionalmente como tales en el marco del Programa sobre Hombre y Biosfera (MaB) de la UNESCO por su interés para la conservación, su potencialidad para aplicar estrategias de desarrollo sostenible y su capacidad para proporcionar conocimientos científicos y técnicos que contri- 
buyan al intercambio mundial de experiencias sobre las mismas". Las Reservas son áreas propuestas por el Gobierno Nacional a solicitud de los Gobiernos de las Comunidades Autónomas y deben satisfacer una serie de requisitos para que sean admitidas en la Red Mundial. Deben cumplir tres funciones complementarias:

Función de conservación: para proteger los recursos genéticos autóctonos, las especies animales y vegetales, los ecosistemas, los paisajes y los recursos culturales.

Función de desarrollo: a fin de reconciliar la conservación con el uso sostenible de los recursos, promoviendo para ello una estrecha cooperación entre gestores, investigadores, comunidades y agentes locales.

Función logística: para incrementar y difundir las actividades de investigación, educación, formación y vigilancia continua.

\section{Administración y Gestión del Parque Natural}

\section{Planificación}

La intervención pública en Espacios Naturales Protegidos en Andalucía se establece mediante dos mecanismos: el desarrollo de un soporte legal que sirve de marco a las actuaciones públicas y privadas y los instrumentos de planificación específicos, que, como complemento a este marco legal general, concretan la capacidad de actuación y promoción del desarrollo en aquéllos.

La Ley $2 / 1989$, de 18 de Julio, por la que se aprueba el Inventario de Espacios Naturales Protegidos de Andalucía y se establecen medidas adicionales para su protección en el ámbito de la Comunidad Autónoma andaluza, ha dado cobertura al primero de estos mecanismos de actuación pública.

Su adaptación y concreción, a cada espacio natural en particular, es objetivo de los respectivos Planes de Ordenación de Recursos Naturales y de los Planes Rectores de Uso y Gestión. La Consejería de Medio Ambiente ha venido realizando desde el año 1989 un notable esfuerzo en la realización de los citados planes para el conjunto de espacios protegidos de la Red, que han visto su aprobación definitiva, de modo progresivo, por el Consejo de Gobierno de la Junta de Andalucía.

En el caso del Parque Natural Marítimo-Terrestre de Cabo de Gata-Níjar, la declaración inicial se produjo mediante el Decreto 3/4/1987. La citada Ley 2/1989 ratificó la declaración ampliando los límites inicialmente establecidos.

Mediante el Acuerdo del Consejo de Gobierno, de 30 de enero de 1990, se autoriza e insta a la Agen- cia de Medio Ambiente a elaborar los PORNs y los PRUGs. El PORN del Parque de Cabo de Gata-Níjar fue aprobado provisionalmente por el Comité de Acciones Integradas para el Ecodesarrollo en su reunión de 7 de octubre de 1993, oída la Junta Rectora y los Ayuntamientos implicados y consultados los intereses sociales, institucionales y ciudadanos personados en el procedimiento de exposición pública.
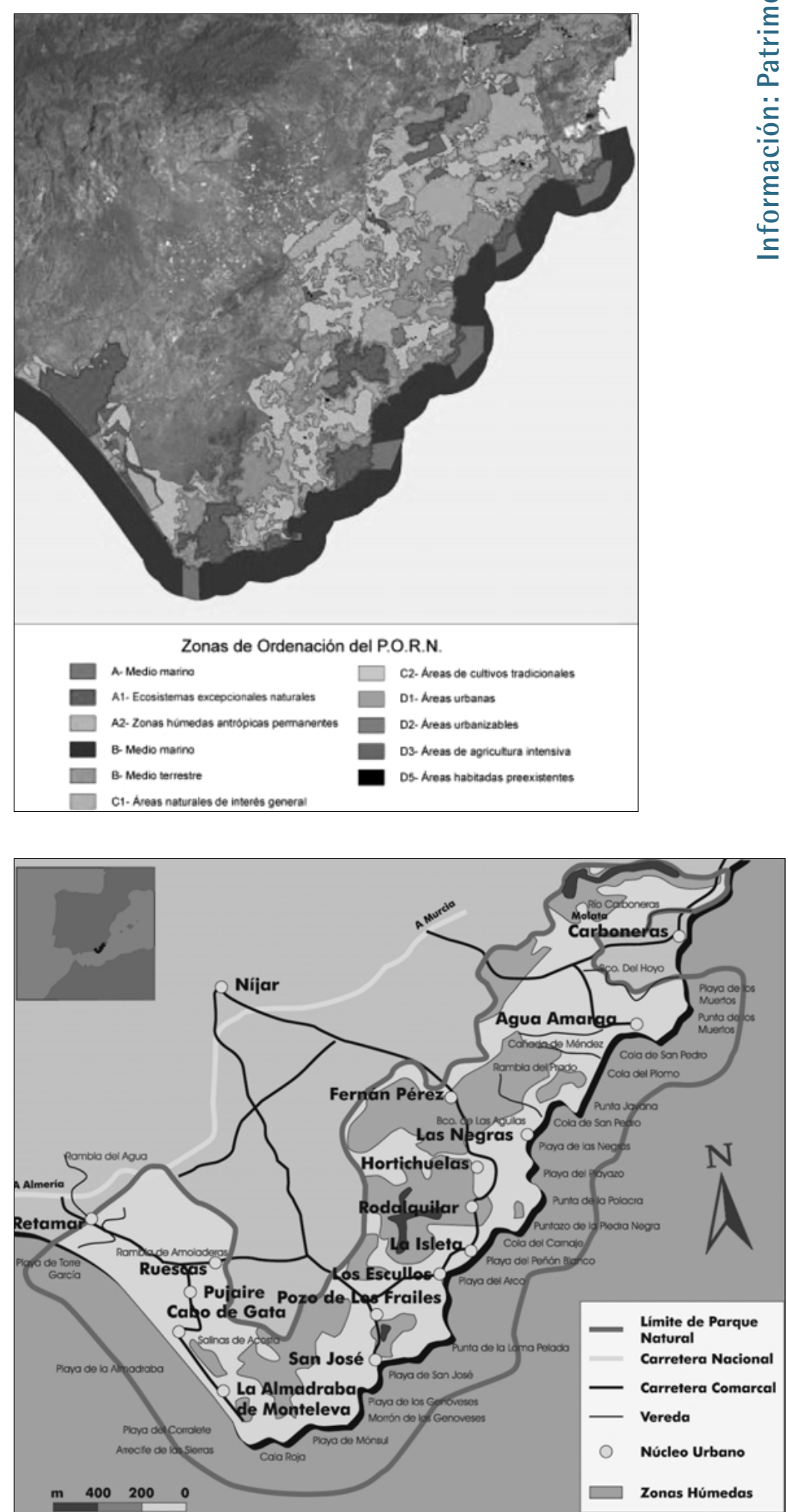


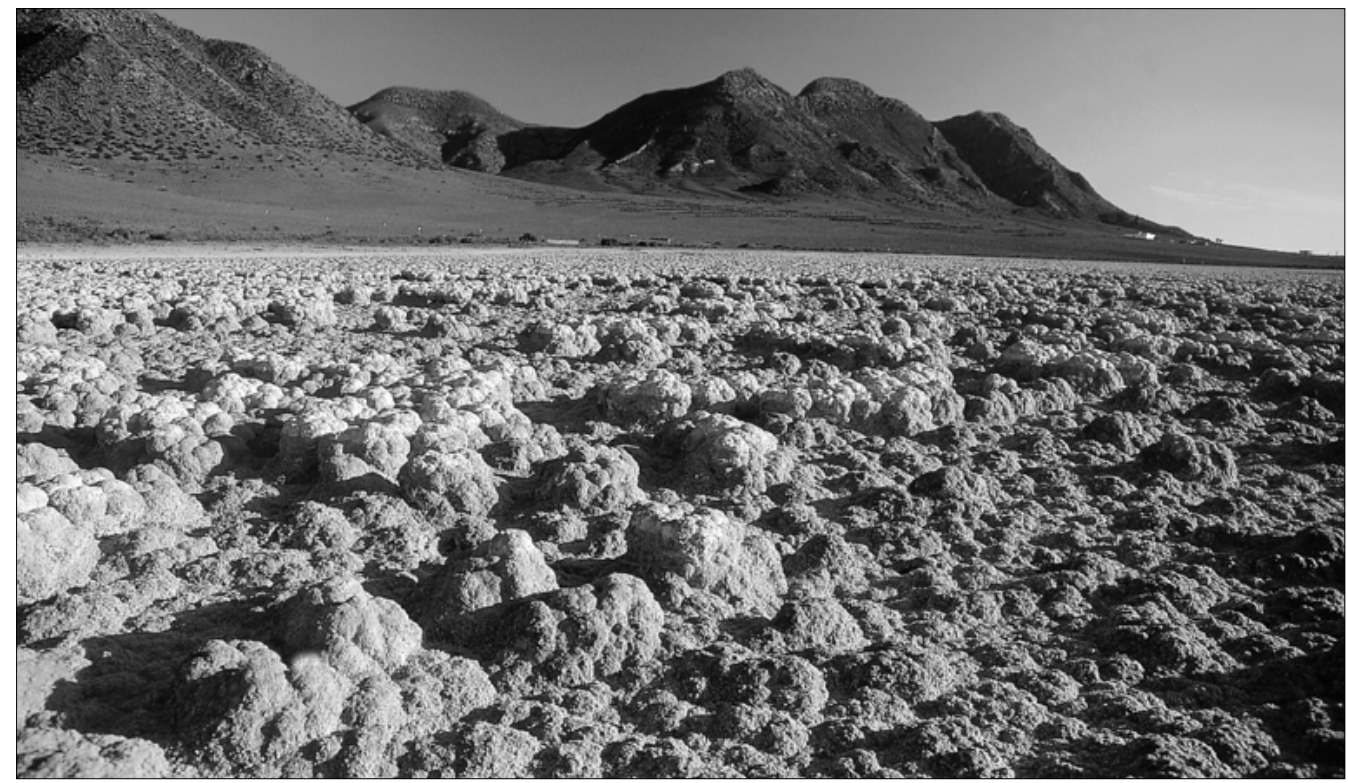

El PRUG fue aprobado por la Junta Rectora del Parque en su reunión de 16 de diciembre de 1992 y, tras su exposición pública, elevado, junto con el PORN al Consejo de Gobierno para su aprobación definitiva.

Con la aprobación y publicación de ambos planes se da cumplimiento al mandato establecido en la Ley 2/89 y se cumple, además, con el espíritu de la Estrategia de Acción para la Red Mundial de Reservas de la Biosfera, que considera como aspecto esencial y clave para la correcta gestión de las mismas la existencia de un marco general de planificación y ordenación legalmente formulado y social e institucionalmente consensuado.

Las normas recogidas en los planes establecen una regulación genérica y específica de los usos y actividades en el suelo no urbanizable y propician una protección efectiva de los recursos naturales. Del mismo modo orientan y establecen las directrices de los programas básicos de actuación pública sobre el espacio.

Ambos planes delimitan, atendiendo a criterios de calidad y fragilidad ambiental, cuatro tipos de zonas dentro del medio terrestre del Parque Natural, con diferentes criterios de uso y conservación, y dos en el medio marino, la vigencia de ambos planes, prorrogada cuatro años en el caso del PRUG, se extiende hasta octubre del 2002, razón por la que la Consejería de Medio Ambiente ha contratado con la Universidad de Almería la adecuación de la citada normativa de ordenación y Gestión, al tiempo que impulsa la redacción del Plan de Desarrollo sostenible del Parque Natural que deberá estar finalizado en el 2003.

\section{Programa de Investigación}

El Parque Natural Cabo de Gata-Níjar presenta unas características físico-ambientales y ecológicas extra- ordinariamente singulares, condicionadas por su carácter árido o subdesértico. No existe en la actualidad un nivel de conocimiento adecuado sobre las relaciones y procesos ecológicos que acontecen en este tipo de sistemas, sin duda entre los de mayor diversidad biológica y endemicidad de la península y del continente europeo.

Los modelos clásicos de gestión del territorio, contrastados con cierto éxito en otras latitudes y tendentes a evaluar la capacidad de acogida del medio para la implantación de actividades humanas, son, para este tipo de medios, de muy difícil extrapolación.

Conscientes de esta realidad, la investigación en el ámbito del Parque, y, en general, en toda la zona subdesértica de la provincia de Almería, constituye una de las principales líneas de acción de la Consejería de Medio Ambiente. Todo ello, además, condiciona que el Programa de Investigación del Parque haya centrado, con carácter prioritario, su atención en aspectos básicos, pero esenciales, como el levantamiento y análisis de la información a escalas de bastante detalle (1// 0.000 o inferiores) en los siguientes aspectos, dando con ello prioridad al conocimiento de los recursos como instrumento fundamental para dirigir las propuestas de manejo:

- Factores climáticos y microclimáticos. Efectos sobre el medio.

- Suelos. Cartografía, Potencialidades. Erosión y salinización. Conservación y regeneración.

- Recursos florísticos y faunísticos. Procesos ecológicos.

- Biología marina.

- Ordenación agro-hidrológica. Análisis de capacidad de carga ganadera. etc..

El medio marino, por su parte, ha sido objeto de una atención específica. Así, y como continuación 
del trabajo de investigación ya realizado relativo a la "propuesta de ordenación ecológica de la franja submarina del Parque", que sirvió de base para la ordenación que desde el PORN se realiza en su ámbito submarino, se ha realizado un ambicioso trabajo de investigación sobre sus fondos centrado en las praderas de fanerógamas.

\section{Programa de Aprovechamiento}

El Parque Natural Cabo de Gata-Níjar alberga un territorio cuya titularidad es privada en algo más del 85 \%. Este factor condiciona que el Programa de Aprovechamientos se oriente más hacia la ordenación de la explotación de los recursos forestales, cinegéticos, agrícolas, ganaderos y pesqueros realizada por gestores privados, utilizando protocolos y convenios de colaboración con estos, al objeto de orientar las practicas y dar apoyo técnico a los mismos.

La gestión, por otro lado, de los terrenos de titularidad pública, está decididamente orientada a la conservación más que a la explotación de los recursos. Ello no excluye la intervención en una serie de sectores productivos considerados estratégicos para el futuro del Parque, como el pesquero, llevando a cabo actuaciones positivas para la recuperación de caladeros (instalación de arrecifes artificiales, etc.).

\section{Programa de Conservación}

El Programa de Conservación tiene como objetivos generales:

- Conservación de los ecosistemas marítimos y terrestres del Parque y recuperación de las especies históricamente desaparecidas mediante programas de rescate genético de especies en peligro de extinción o endémicas.

- Restauración activa de áreas degradadas, especialmente aquellas con procesos erosivos graves, y restauración hidrológico-ambiental.

- Prevención, vigilancia y protección frente a los incendios forestales.

- Compra y adquisición de terrenos en áreas de interés.

Se enmarca aquí el reciente logro de un programa Life que incide sobre los principales espacios del Parque $\mathrm{Na}$ tural procurando su mejora y, en ocaciones, la restauración de los valores perdidos.

El medio marino, como se ha señalado, merece una especial atención en el Programa de Conservación.

El subprograma de instalación de arrecifes artificiales, iniciado con carácter piloto en el ámbito marino protegido del Parque Natural durante los años 1993 y 1994, y cuya finalidad prioritaria es incrementar los recursos biológicos mediante la creación de habitats favorables para la vida marina, pretende ser extendido a otras áreas de interés del Parque: Amoladeras, Cabo de Gata, Almadrava de Monteleva, San José, La Isleta del Moro- Los Escullos, Las Negras y Agua Amarga. Para ello, la Consejería de Medio Ambiente cuenta con los resultados del trabajo. Éste se desarrollará en el marco del Programa "Almería 2002-2005", procurando una instalación de módulos en siete zonas más durante la década 2002-2012.

\section{Programa de Uso Público}

La demanda de uso público en el Parque Natural Cabo de Gata-Níjar presenta un constante crecimiento en estos últimos años, tanto en su vertiente estrictamente recreativo-turística, como en la didáctica y científica. El incremento constante de visitas al Parque refleja un crecimiento del flujo anual de usuarios de las instalaciones de uso público.

La Consejería de Medio Ambiente asume el deber de proporcionar, de manera directa o indirecta (promoción y apoyo a iniciativas privadas), los medios técnicos y humanos necesarios para garantizar el derecho a disfrutar el Parque Natural de un modo compatible con el mantenimiento de los recursos naturales y culturales, y en tal sentido viene realizando un notable esfuerzo inversor desde que en 1987 definieran las Directrices de Acondicionamiento y Explotación Turística del Parque.

El Programa de Uso Público del Parque, redactado y pendiente de aprobación para 1998, se orienta claramente hacia la ordenación del uso turístico recreativo y la potenciación de la Educación Ambiental, dotando al Parque de un conjunto de equipamientos e instalaciones que permitan dar al tiempo de ocio un carácter enriquecedor desde el punto de vista educacional. Esta estrategia de actuación se ve en la actualidad reforzada por la catalogación como Geoparque en el 200 I y con la incorporación del Parque a la Red Mundial de Reservas de la Biosfera cuya estrategia sitúa el "Fomento de la educación, la concienciación pública y la participación" entre las líneas de acción prioritarias de la red.

El Programa de Uso Público del Parque plantea como funciones esenciales:

- Ofrecer escenarios pedagógicos

- Ofertar instalaciones y servicios (centros y unidades de interpretación, aulas, rutas y senderos, miradores, etc.).

- Proporcionar apoyo logístico y técnico a los usuarios.

- Ofertar materiales didácticos (guías, audiovisuales, publicaciones, señalización).

En este sentido puede decirse que el Parque cuenta ya en el 200I, con un nivel de equipamiento para el uso público excepcionalmente importante. 


\title{
Equipamientos de uso público en el Parque Natural de Cabo de Gata-Níjar
}

a) En funcionamiento:

- Centro de Visitantes de Las Amoladeras

- Kioskos/Puntos de Información (5) en Noria del Pozo de los Frailes, Las Sirenas, La Amatista, Los Muertos y La Isleta del Moro. Además 4 kioskos/Puntos de Información desmontables y móviles

- Oficina de Información y Tienda Verde: Rodalquilar

- Senderos señalizados (24)

- Miradores (8) de La Isleta del Moro, Las Amoladeras, Punta de los Muertos, Las Sirenas, La Amatista, Rodalquilar, La Joya y Los Negros

- Sitio de Interés etnológico: Pozo de los Frailes

- Vivero: Rodalquilar

- Observatorios ornitológicos (2): Las Salinas I y Las Salinas II

- Señalización básica

- Centro de Educación Ambiental "El Bujo"

- Aula del mar "El Corralete"

- Jardín Botánico "El Albardinal"

- Punto de Información "Rodalquilar"

b) En obras y/o pendientes de instalaciones

- Albergue ornitológico "Las Amoladeras"

- Senderos interpretativos de georecursos

- Señalización prioritaria

- Centros de Servicios del Litoral (2) en Mónsul y Torregarcía

c) Previsiones futuras:

- Centro de recuperación de Especies Marinas.

- Miradores (6) de Vela Blanca, La Fabriquilla, Mesa Roldán, Risco de Bornos, Loma Pelada y Las Salinas III

- Centro de Medio Marino: Castillo de San Felipe

- Centro Fitoturístico: El Cornical

- Villa Didáctica - Turística - Ambiental: Rodalquilar

- Área recreativa: Mesa Roldán

- Puntos de Información (7) en El Algarrobico, La Cueva del Pájaro, Fernán Pérez, Los Negros, San Miguel, San José y Carboneras

- Señalización terrestre complementaria

- Señalización del medio marino

\section{Fotografías:}

\author{
E. López Carrique, \\ J. Bayo Valdivia, \\ J. Antonio Fernández, \\ A. García Cruz, \\ J. Guirado Romero \\ J. M. López Martos
}

